\title{
The research of co-evolution mechanisms between cross-border e-commerce and manufacturing cluster: An Agent-based model
}

\author{
Li-ping QIU ${ }^{1}$, Li-hua YANG ${ }^{* 1}$ \\ ${ }^{1}$ The Business School \\ Ningbo University \\ Ningbo, China
}

\begin{abstract}
China's cross-border e-commerce industry presents the development trend as the service industry clusters, and interacts closely with the traditional manufacturing clusters. However, the mechanism for the coordinated evolution of the two kinds of clusters is not clear yet. This paper defines the cross-border e-commerce and the manufacturing cluster under collaboration as a complex socio-economic adaptation system that includes manufacturers, service providers, government behaviors and market demands. An agent-based collaborative model is designed by three types of agents and four driving interaction mechanisms, then the co-evolution mechanisms are observed and discussed in the process of dynamic evolution. Based on the rationality and feasibility of the model, the research explored the trend of co-evolution through scenario simulations and analysis, improved the mechanisms of co-evolution, and pointed out that cross-border e-commerce is one of the ways to transform and upgrade the manufacturing cluster. The conclusion of the study provides evolutionary ideas for export-oriented industrial clusters to coordinate with the cross-border e-commerce.
\end{abstract}

\section{INTRODUCTION}

Manufacturing industry develops in the form of clusters is a typical feature of China's open economy [1]. After experiencing rapid growth, China's export-oriented manufacturing clusters often suffer from their own development due to "low-end lock-in" [2] [3], and urgently need to find ways to transform and upgrade.

Previous studies have shown that the boundary between manufacturing and producer services is gradually blurring and there is a convergence trend ${ }^{[4]}{ }^{[5]}[6]$. In particular, the development of China's cross-border e-commerce has already shown the development trend as the producer service industry ${ }^{1}$, which provides a possible path for the transformation and upgrading of the manufacturing cluster, but the mechanism of the coordinated evolution of the two is not clear yet.

Industrial clusters have been generally recognized as a complex adaptive system ${ }^{[7]}$. From the perspective of the complex adaptive system (CAS), the previous studies focused on the industry (enterprise, organization and environment, etc. ${ }^{[8] ~[9] ~[10] ~[11] ~ a n d ~ t h e ~ i n t e r-i n d u s t r y ~}$ collaborative evolution mechanism [12] [13]. Taking cross-border e-commerce and manufacturing clusters as the research objects of inter-industry collaboration, CAS can provide a feasible theoretical basis for studying the co-evolution mechanism of two clusters.

\footnotetext{
1 "The 13th Five-Year Development Plan for E-commerce" http://www.mofcom.gov.cn/article/b/d/201612/20161202425267.shtml
}

Agent based modeling and simulation (ABMS) is a toolkit that applied the concept of CAS into the basic structure of simulation models ${ }^{[14]}$, used to analyze complex adaptive systems and emerging phenomena in social sciences ${ }^{[15]}$. ABMS has been applied in the field of industrial cluster research, for example, Vito et al. used Agent-based simulation technology to study the emergence and evolution of the innovation process in industrial clusters ${ }^{116]}$; Liu Wenrong proposed the technology innovation mechanism system (TISSM), three agent-based models of technology innovation motivation, diffusion and symbiosis mechanism were constructed respectively [17]; Sun Hao et al. constructed an Agent-based e-commerce ecosystem model to visually show the evolutionary relationship ${ }^{[18]}$. In conclusion, ABMS has not expanded the research on cross-border e-commerce service industry, and the relative research on collaboration between cross-border e-commerce and manufacturing cluster as a complex adaptive system is even rarer.

This study aims to develop an agent-based collaboration model of cross-border e-commerce and manufacturing cluster, which can observe the dynamic evolution process of enterprises, clusters and environments in the model through simulation, and identify the mechanism of the co-evolution of two clusters. With a view to providing a reference co-evolution model for China's manufacturing clusters, especially those industrial clusters with export-oriented characteristics, to transformation and upgrading.

*Email: yanglihua@nbu.edu.cn 


\section{CONCEPTUAL MODEL AND SIMULATION DESIGN}

\section{A. Conceptual model design}

The collaboration model of cross-border e-commerce and manufacturing cluster is a complex socio-economic adaptation system that includes manufacturers, service providers, government actions, and market demands ${ }^{[19]}$. The model is composed of three kinds of agents, namely supplier, sever and context. Among those agents, supplier, traditional export server and the context constitute a manufacturing cluster; cross-border e-commerce server and the context constitute a cross-border e-commerce service industry cluster; the context agent include government actions and market demands.

The basic idea of the Agent-based modeling and simulation (ABMS) is object-oriented programming. All subjects are composed of attributes and behaviors. The composition of attributes and behaviors of those three types of agents show as follows.

\section{1) Supplier Agent}

The supplier agents occupies a large amount of cluster resources in the manufacturing cluster, supplemented by various types of productive service agents (sever) to realize the flow of resources. Distinguishes the supplier according to actual economic conditions, this article assume that supplier agents in the same size that have similar behaviors in the initial stage. However, the attributes and behaviors of each supplier agents are nonlinearly evolved when the evolution progresses. Specific attributes and behaviors are shown in Table I.

TABLE I. INTRODUCTION OF SUPPLIER CLASS PARAMETERS AND MAIN METHODS

\begin{tabular}{|c|c|l|}
\hline Supplier & Name & \multicolumn{1}{c|}{ Explanation } \\
\hline \multirow{4}{*}{ Attributes } & Scale & The size of the supplier's scale \\
\cline { 2 - 3 } & Funds & Available funds \\
\cline { 2 - 3 } & Income statement & Record income levels of different export models \\
\cline { 2 - 3 } & Reproduction cycle & Time required to produce current production \\
\cline { 2 - 3 } & Output & Current manufacturer's output capacity \\
\hline \multirow{4}{*}{ Behaviors } & Yield adjustment & $\begin{array}{l}\text { Solve the Cournot model based on decreasing cluster cost, adjust output and } \\
\text { nire }\end{array}$ \\
\cline { 2 - 3 } & Export mode selection & Choose traditional export methods or cross-border e-commerce export \\
\cline { 2 - 3 } & $\begin{array}{c}\text { Reproduction the } \\
\text { production of goods }\end{array}$ & Complete the production of goods \\
\cline { 2 - 3 } & \begin{tabular}{c} 
Expansion and exit \\
\cline { 2 - 3 }
\end{tabular} & Adjust the scale or exit the market according to its own attributes \\
\hline
\end{tabular}

\section{2) Sever Agents}

Two types of server agents are considered in the collaboration model, which are traditional export server agent and cross-border e-commerce server agent. The former exists in the manufacturing cluster, and the latter emerges from the collaboration model.
As the carrier of resource flow, both kinds of sever agents have the same attributes and behavior, but differences in attribute parameters and behavior selections (see Table II).

TABLE II. SEVER CLASS PARAMETERS AND MAIN METHODS

\begin{tabular}{|c|c|c|}
\hline Sever & Name & Exnlanation \\
\hline \multirow{5}{*}{ Attributes } & Observation location & Market observation point for server agents to match supply and demand \\
\hline & Vision & The scope of market observation for server agents to match supply and demand \\
\hline & Service fee & Record the various fund levels of server agents \\
\hline & Service point & Match the location of overseas demand \\
\hline & Service time & Total time to complete the service \\
\hline \multirow{4}{*}{ Behaviors } & $\begin{array}{l}\text { Supply and demand } \\
\text { matching }\end{array}$ & $\begin{array}{l}\text { The server agents matches all the demand obtained according to the attributes } \\
\text { with the output of the cooperative supplier agents to obtain the optimal } \\
\text { cooperation target }\end{array}$ \\
\hline & Fund transfer & Reflect the differences in behavior choices of different server agents, see 2.2.2. \\
\hline & Commodity delivery & Complete the transfer of goods from the supplier to the demand \\
\hline & Context perception & $\begin{array}{l}\text { Perceive the information transmitted by the agents from context, adjust } \\
\text { their own behavior }\end{array}$ \\
\hline
\end{tabular}

3) Context Agents

The context agents are composed by two sides, in which the government behavior from the supply side plays a guiding role, and the overseas market demand on the demand side determines the target of the transaction behavior. Also, the context agents are modeled as the system operating context. Specific attributes and behaviors are shown in Table III.

TABLE III. CONTEXT CLASS PARAMETERS AND MAIN METHODS

\begin{tabular}{|c|c|c|}
\hline \multirow{3}{*}{ Context } & Name & \multicolumn{1}{c|}{ Explanation } \\
\hline \multirow{3}{*}{ Attributes } & \multicolumn{2}{c|}{ Supplier side } \\
\cline { 2 - 3 } & Demand & \multicolumn{1}{c|}{ Current customer demand in overseas markets } \\
\cline { 2 - 3 } & \multicolumn{1}{|c|}{ Demade } \\
\cline { 2 - 3 } & Supervision & $\begin{array}{l}\text { The degree of monitoring and management of cross-border e-commerce export } \\
\text { behavior by customs }\end{array}$ \\
\hline
\end{tabular}




\begin{tabular}{|c|c|l|}
\hline \multirow{4}{*}{ Infrastructure } & $\begin{array}{l}\text { Government-led construction of public services such as cross-border parks, overseas } \\
\text { warehouses etc. }\end{array}$ \\
\cline { 2 - 3 } & Efficiency & Measures to accelerate the transaction rate \\
\hline \multirow{4}{*}{ Behaviors } & Add demand & Add demand-side customer needs to the environment \\
\cline { 2 - 3 } & Change demand & Inform server agents of demand changes and complete supply and demand matching \\
\cline { 2 - 3 } & $\begin{array}{c}\text { Add supplier and } \\
\text { sever agents }\end{array}$ & Add the agents of supply side to the environment \\
\cline { 2 - 3 } & $\begin{array}{c}\text { Changes context } \\
\text { agents behavior }\end{array}$ & Inform supplier and sever agents of changes in government behavior \\
\hline
\end{tabular}

\section{B. Simulation design}

\section{1) Model structure}

The Repast Simphony 1.0 platform and Java language are used to implement the model. According to Repast design requirements, the elements of the model are divided into: Context Object, Space Object and Agent
Object. There is one instantiated context object, at least one instance space object and many different agent objects in each Repast model ${ }^{[20]}$. The structure of nine source codes of the three objects of the simulation model in this paper is shown in Table IV.

TABLE IV. REPAST SIMULATION MODEL STRUCTURE TABLE

\begin{tabular}{|c|l|}
\hline Objects & \multicolumn{1}{c|}{ Source Code } \\
\hline \multirow{2}{*}{ Context object } & Context definition program: WorldScape.java \\
\cline { 2 - 3 } Space object & Context definition program: WorldSpace.java \\
\hline \multirow{3}{*}{ Agent objects } & Space (requirement) definition program: CustMat.java \\
\cline { 2 - 3 } & Space display calling program: CustStyle2D.java \\
\cline { 2 - 2 } & Supplier definition program: Supplier.java \\
\cline { 2 - 3 } & Traditional trade sever definition program: TSever.java \\
\cline { 2 - 3 } & Cross-border e-commerce sever definition program: ESever.java \\
\cline { 2 - 3 } & Interactive subject class definition program: Ship.java \\
\cline { 2 - 2 } & Global variable observation statistics class definition program: AllAgent.java \\
\hline
\end{tabular}

\section{2) Process and driving interaction mechanism}

The structure and process of the agent-based collaboration model of cross-border e-commerce and manufacturing cluster (see Fig.1), including: The supplier agents determine the export mode, contact the corresponding server agents of the traditional export or

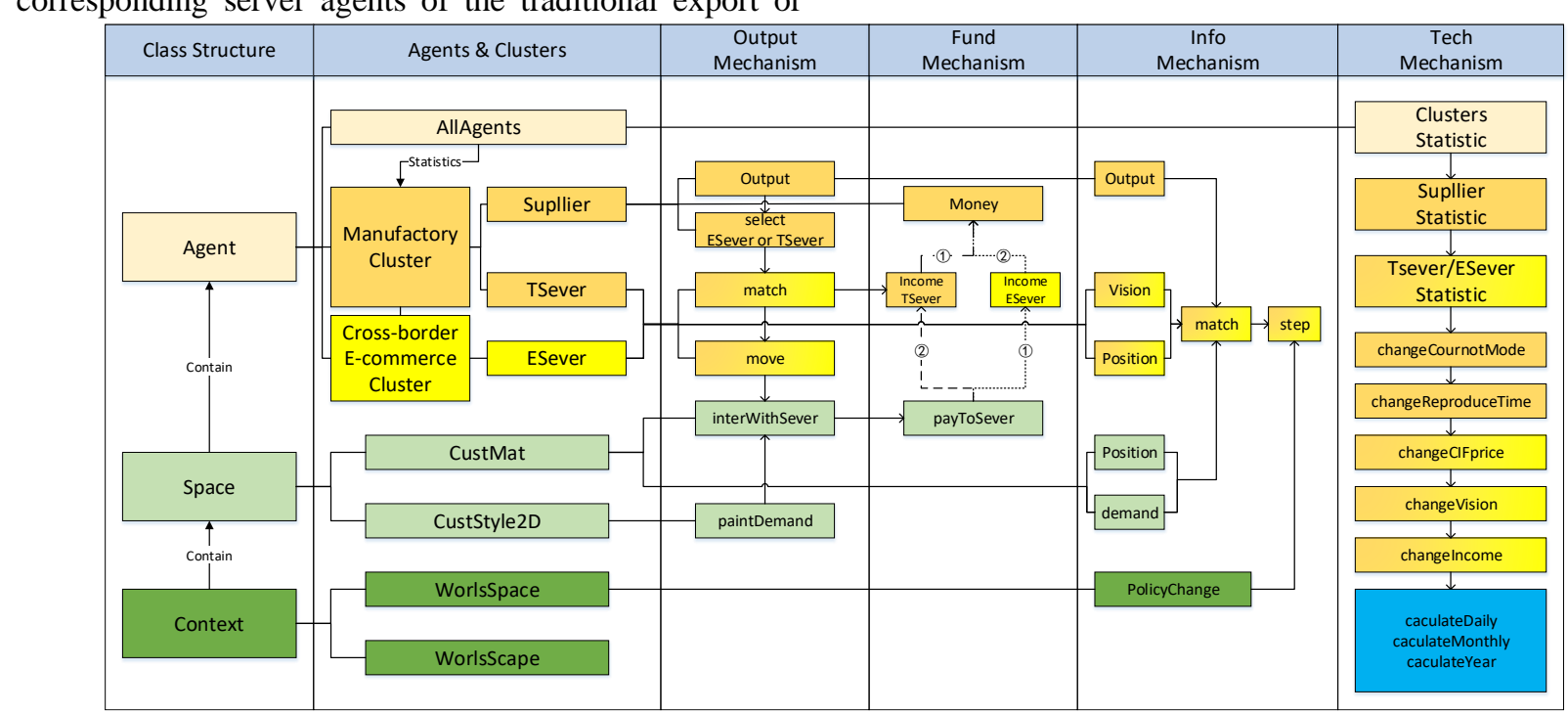

Figure 1. The structure and process of the model the cross-border e-commerce, then server agents connect with the overseas customer, the demand side of context agents to complete foreign economic and trade activities. The specific interaction mechanisms to achieve the process is designed as follows: 


\section{a) Commodity circulation mechanism}

The most basic flow of the commodity circulation mechanism is to complete the flow of goods from supplier to server to customer.

In addition, supplier agents' production behavior is an important factor affecting the circulation of commodities. In this research the production model adopts the Cournot equilibrium model based on decreasing cluster cost ${ }^{[21]}$.

Suppose that in simulation year $Y_{t}$, three types of supplier agents exist in model: large scale $S_{1}$ and its quantity $n_{1}$, medium scale $S_{2}$, quantity $n_{2}$ and small scale $S_{3}$, quantity $n_{3}$. For a perfectly competitive market, there are $n$ supplier agents that produce homogeneous products with no difference. The marginal cost in the cluster is $c_{0}$, the parameters of the linear inverse demand function are $a, b$, then the total output of the cluster in the current year $O_{c, t}$ will be:

$$
O_{c, t}=\frac{\left(\frac{S_{1}}{S_{3}} n_{1}+\frac{S_{2}}{S_{3}} n_{2}+n_{3}\right) \times\left(a-\frac{c_{0}}{\sqrt[3]{\frac{S_{1}}{S_{3}} n_{1}+\frac{S_{2}}{S_{3}} n_{2}+n_{3}}}\right)}{b\left(\frac{S_{1}}{S_{3}} n_{1}+\frac{S_{2}}{S_{3}} n_{2}+n_{3}+1\right)}
$$

Each type of supplier agents' output in the current year $O_{S i, t}$ will be:

$$
O_{S i, t}=\frac{S_{i}}{S_{3}} \times \frac{a-\frac{c_{0}}{\sqrt[3]{\frac{S_{1}}{S_{3}} n_{1}+\frac{S_{2}}{S_{3}} n_{2}+n_{3}}}}{b\left(\frac{S_{1}}{S_{3}} n_{1}+\frac{S_{2}}{S_{3}} n_{2}+n_{3}+1\right)} \quad(i=1,2,3)
$$

In collaboration model, the production behavior will be adjusted in each simulation year.

\section{b) Fund circulation mechanism}

The fund circulation mechanism is a reverse commodity circulation mechanism, which is conducted by the "customer to server to supplier".

Under the traditional export, server agent pre-paid goods to supplier by market prices, and gain benefits after interacting with customers. However, under the cross-border e-commerce, server interact with customers before conducting capital transmission (see Fig.1).

In the simulation year $Y_{t}$, the market price $P_{c, t}$ is calculated by:

$$
P_{c, t}=\frac{a+\left(\frac{S_{1}}{S_{3}} n_{1}+\frac{S_{2}}{S_{3}} n_{2}+n_{3}\right) \times \frac{c_{0}}{\sqrt[3]{\frac{S_{1}}{S_{3}} n_{1}+\frac{S_{2}}{S_{3}} n_{2}+n_{3}}}}{\frac{S_{1}}{S_{3}} n_{1}+\frac{S_{2}}{S_{3}} n_{2}+n_{3}+1}
$$

The CIF price ${ }^{1} P_{C I F, t}$ calculated by server agents $\left(T S_{n}, E S_{m}\right)$ is:

$$
P_{C I F, t}=\left(\frac{C_{\text {cos }}+C_{\text {trans }}}{1-R_{\text {fixed }}-R_{\text {insu }}-I_{\text {exp }}}\right)
$$

Assume a supplier agent $S_{n, i}$, its output is $O_{S, n, i}$, and its actual transaction volume is $O_{S, n, i}^{\prime}\left(O_{S i}^{\prime} \leq O_{S i}\right)$. In $Y_{t}$, $S_{n, i}$ get revenue through the traditional export $I_{C, t, T S}$ will be:

$$
I_{C, t, T S}=\sum_{n}\left(O_{S, n, i}^{\prime} \times P_{c, t}\right) \quad(i=1,2,3)
$$

\footnotetext{
1 The CIF pricing (cost fee plus insurance fee plus freight), referring to the basic calculation method of international trade practice. Among them, $C_{c o s}$ is the variable cost, $C_{\text {trans }}$ means freight, $R_{\text {fixed }}$ is the fixed rate, $R_{\text {insu }}$ means insurance rate, $I_{\text {exp }}$ is the expected rate of return.
}

Revenue through cross-border export $I_{C, t, E S}$ will be:

$I_{C, t, E S}=\sum_{n}\left(O_{S, n, i}^{\prime} \times P_{C I F, t} \times R_{r e}\right) \quad(i=1,2,3)$

$R_{r e}$ means the revenue ratio of supplier and server.

c) Information-driven mechanism

Information search capability (field of view) is an important influencing factor that affects the server agents' abilities like matching the supply and demand, responding to environmental changes.

Assuming that the scope of vision of traditional export server agents in the cluster is narrow, and the horizon of cross-border e-commerce is relatively broad. In the simulation year $Y_{t}$, the traditional export server agent $T V_{n}$ has a vision of $V_{T S, n, t}$, the cross-border e-commerce server agent $E S_{m}$ has a vision of $V_{E S, m, t}$, then the average cluster vision level for that year $V_{C, t}$ will be:

$$
V_{C, t}=\frac{\sum_{n} V_{T S, n, t}+\sum_{m} V_{E S, m, t}}{n+m}
$$

Supervision of government actions among environmental entities $\alpha$ will affects server agents' variable costs $C_{\cos , t}$ :

$$
C_{c o s, t}=\left\{\begin{array}{cl}
P_{c, t} & , \alpha=0 \text { or escape }=1 \\
P_{c, t} \times\left(1-\operatorname{Tax}_{t}+\operatorname{ReTax}_{t}\right), & 1>\alpha>0 \text { and escape }=0, \text { or } \alpha=1
\end{array}\right.
$$

In formula 8 , "escape" reflects the standardization degree of server agents, which will affect the variable cost of $C_{c o s, t}$, the cross-border export earnings of $I_{C, t, E S}$ and the customs clearance time of $T_{c o, t}$.

Infrastructure construction $\beta$ will affects fixed rates of $R_{\text {fixed, } t}$ :

$$
R_{\text {fixed }, t}=(1-\beta) R_{\text {fixed }, t-1} \quad \beta \in[0,0.5)
$$

Efficiency construction $\gamma$ will affects the customs clearance time of $T_{c o, t}$ :

$$
T_{c o, t}=T_{c o, t-1}-\gamma \quad \gamma \in[0,0.5)
$$

\section{d) Technological innovation mechanism}

In the co-evolution model, technological innovation will affect the reproduction time of the supplier agent and the service time of the server agent, which means the improvement of the information efficiency driven by the server agent's will affects the production mode of the supplier agent, thus the reproduction time changes, bringing more economic benefits and finally changes in scale.

In the simulation year of $Y_{t}$, the transaction time of the server agents $T S_{n}$ and $E S_{m}$ is divided into transportation time and customs declaration time. In this year, the server agents' service times are $\sigma$ and $\varphi$ respectively, then the average transaction time of $T_{C, t}$ will be:

$$
T_{C, t}=\frac{n \sum_{\sigma}\left(T_{T S, \text { trans }, t}+T_{T S, c o, t}\right) / \sigma^{+}}{n+m} \sum_{\varphi}\left(T_{E S, \text { trans }, t}+T_{E S, c o, t}\right) / \varphi(11)
$$

For supplier agent $S_{n, i}$, the average cluster reproduction time $T_{C r, t}$ will be:

$$
T_{C r, t}=\frac{\sum_{n} \sum_{i} t_{r, n, i}}{n}
$$

3) Model validation 
Considering that the lack of a unified statistical standard for cluster data in China, this article selects the proportion of China's cross-border e-commerce exports from 2013 to 2018 as a percentage of total exports to verify the co-evolution model.

The simulation performs five dynamic verifications on the collaborative model, the simulation obtained the co-evolution trend of the first 6 simulation years as shown in Fig.2 (a).

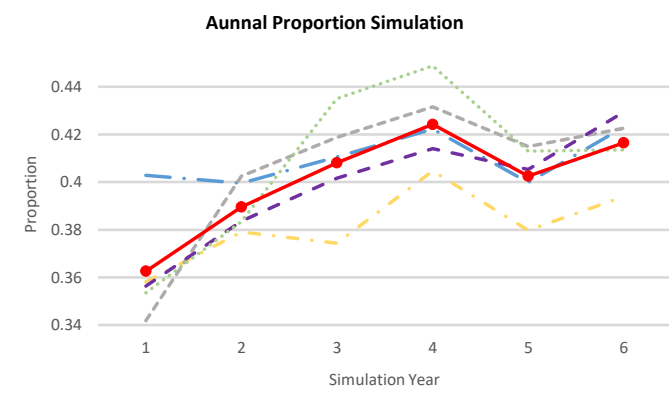

(a)
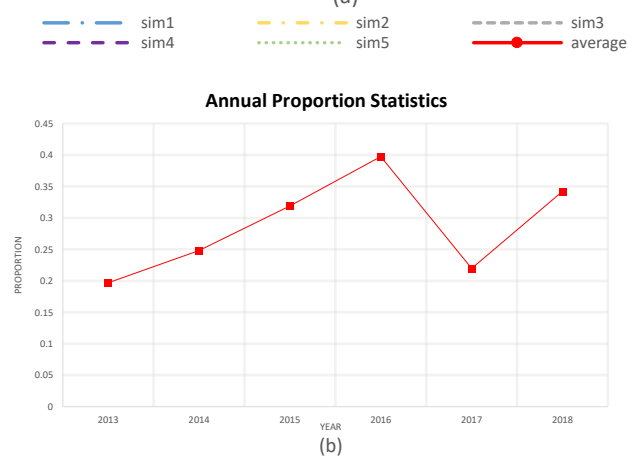

Figure 2. Trends in simulation and statistics of scale proportion

Except the year of 2017, China's cross-border e-commerce exports accounted for a gradual increase in the proportion of total exports ${ }^{1}$ since the establishment of the comprehensive cross-border e-commerce pilot zone in 2013, see Fig.2 (b). The simulation results in Fig.2 (a) reflects the trend well, indicating that the model design basically conforms to the actual economic operation.

\section{SCENARIO SIMULATION RESULTS}

Four scenarios are designed to study and verify the interactive driving mechanisms hypothesized in the previous section, the basic parameters setting can be found in Table V. Considering that the nonlinearity and diversity characteristics of CAS [22] will cause the simulation results to fluctuate, each scenario simulation will run 10 times repeatedly, and the running results are averaged for discussion.

TABLE V. SCENARIO SIMULATION'S SETTINGS

\begin{tabular}{|c|c|c|c|c|}
\hline Parameters & Scenario 1 & Scenario 2 & Scenario 3 & Scenario 4 \\
\hline Mechanism & $\begin{array}{l}\text { Commodity } \\
\text { circulation }\end{array}$ & $\begin{array}{c}\text { Fund } \\
\text { circulation }\end{array}$ & $\begin{array}{c}\text { Information-d } \\
\text { riven }\end{array}$ & $\begin{array}{l}\text { Technological } \\
\text { innovation }\end{array}$ \\
\hline \multirow{2}{*}{$\begin{array}{c}\text { Investigation } \\
\text { parameters }\end{array}$} & \multirow{2}{*}{$O_{c, t}$} & $I_{C, t, T S}$ & \multirow{2}{*}{$V_{c, t}$} & $T_{C, t}$ \\
\hline & & $I_{C, t, E S}$ & & $T_{c r, t}$ \\
\hline $\begin{array}{l}\text { Influence } \\
\text { parameters }\end{array}$ & - & $\mathrm{C}_{\text {trans }}$ & - & - \\
\hline & & $I_{\text {exp }}$ & & \\
\hline
\end{tabular}

1 Source of data: China's total exports come from the National Bureau of Statistics; cross-border e-commerce exports come from the NetEco.

\section{A. Scenario 1}

In Scenario 1, the total output $O_{c, t}$ of the cluster in the simulated year of $Y_{t}$ was used to evaluate the commodity circulation mechanism to see whether the collaborative model promotes the cluster development. Data preprocessing was performed on $O_{c, t}$, and the output in the base year $Y_{0}$ was set as 1 , the corresponding values were calculated sequentially for the remaining simulation years.

The simulation result shows that the total output of the cluster reaches its peak at $Y_{4}$ and then decreases year by year (see Fig.3). The growth rate of the total output of the cluster continues to be less than 0 from $Y_{4}$. The total output in $Y_{10}$ is expected to be $185 \%$ from the total annual output.

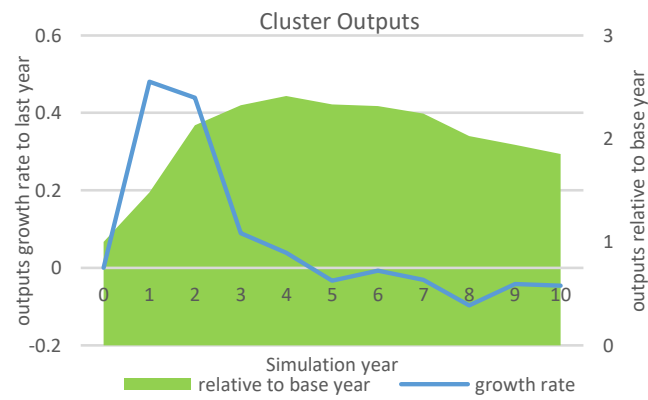

Figure 3. Evolution map of the total output of the cluster

The results show that with the co-evolution of the two clusters, the total output value of the cluster is greatly improved compared to the base year. At the same time, the growth process of the cluster in the simulation process shows the phase characteristics of growth and convergence in the life cycle model ${ }^{[23]}$ of industrial cluster evolution.

\section{B. Scenario 2}

In Scenario 2, the traditional export revenue $I_{C, t, T S}$ and the cross-border e-commerce export revenue $I_{C, t, E S}$ of the supplier agent were used to evaluate the fund circulation mechanism and predict whether cross-border e-commerce will bring additional profits to supplier agents in the manufacturing cluster.

Assuming that the basic annual returns are the same, observe the unit export ratio of the two export models (see Fig.4), as the simulation proceeded, the returns obtained by the manufacturing cluster through cross-border e-commerce exports show a trend of increasing first and then decreasing. In particular, from the simulation year $Y_{6}$, the unit revenue obtained through cross-border e-commerce export is lower than the traditional export revenue, and even dropped to only $86 \%$ of the traditional export revenue by the simulation year $Y_{10}$. 


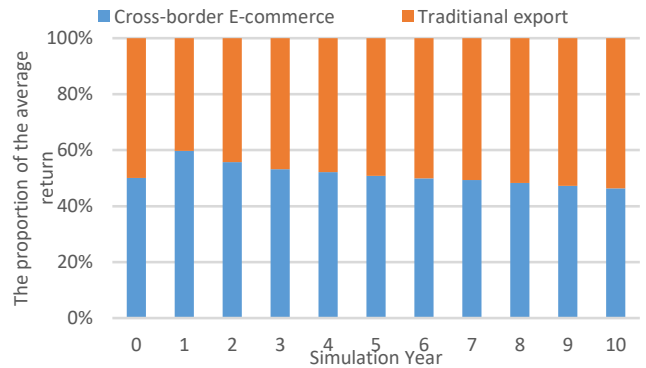

Figure 4. Unit export ratio of the two export models

This finding may not be conducive to the co-evolution of the cluster, because the lower income will affect the export choices of supplier agents, so more parameters are used to analyze the potential problems in the fund interaction mechanism.

This research selected the index parameters of $C_{\text {trans }}$ and $I_{\text {exp }}$ that affect the value of $P_{C I F, t}{ }^{1}$. The theoretical analysis of the fund circulation mechanism believes that under the traditional export model, the unit profit depends on the cost of the cluster, so the value of $I_{C, t, T S}=1$; while under the cross-border e-commerce model, the unit profit and the total revenues are related, so the value of $I_{C, t, E S}$ was specifically observed. Under the standard agent-based collaborative model, $C_{\text {trans }}=4000, I_{\text {exp }}=$ 0.2 .

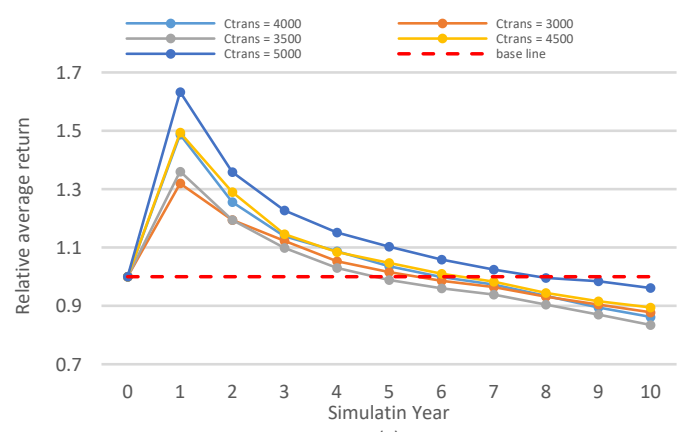

(a)

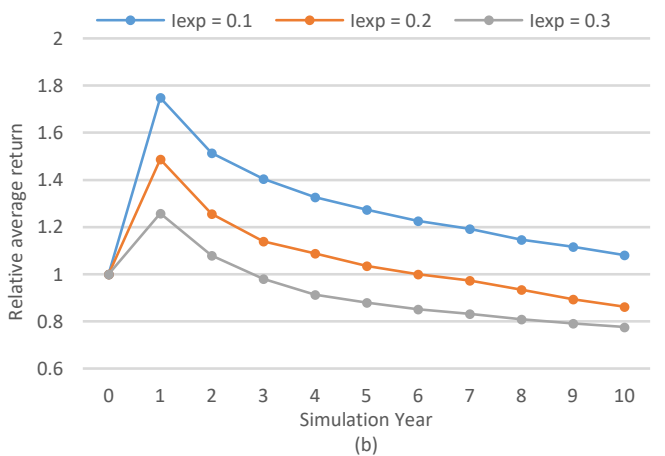

Figure 5. The average unit commodity income obtained by the simulation of two parameters

Freight $C_{\text {trans }}$ generated by logistics caused a nonlinear effect on the relative average return of unit commodities $I_{C, t, E S}$. As shown in Fig.5 (a), the larger the $C_{\text {trans }}$, the higher the simulated value of $I_{C, t, E S}$; when the value of $C_{\text {trans }}$ reduced to 3000 , the simulated value

${ }^{1}$ Among the remaining influencing factors, variable cost $C_{c o s}$ and fixed rate $R_{\text {fixed }}$ are controlled by the information-driven mechanism, and the insurance rate $R_{\text {insu }}$ is a fixed value. of $I_{C, t, E S}$ is higher than the standard model Set value after the simulation year of $Y_{7}$.

As shown in Fig.5 (b), the higher the cross-border e-commerce's expectation of its own revenue, the supplier agents will get lower revenue under the current fund circulation mechanism, which is logical.

The results show that cross-border e-commerce does bring additional unit product profits to the supplier agents in the early stage of the simulation, but the development of the latter reduce its income. In the agent-based collaboration model, the functions of payment, logistics and other service companies are integrate into the behavior of sever agents. The above findings may help us analyze the optimization of cross-border e-commerce service system and the improvement of capabilities in the next chapter.

\section{Scenario 3}

In Scenario 3, the average horizon level $V_{C, t}$ of server agents in the cluster in the simulation year $Y_{t}$ was used to evaluate the information-driven mechanism. Data preprocessing is performed on $V_{C, t}$, and the average visual field level of the base year $(t=0)$ is set to 1 , and the corresponding values are calculated in turn for the remaining simulated years.

The average horizon level $V_{C, t}$ of the server agents in the cluster shows an increasing trend year by year (see fig.6). It is estimated that the average visual field level of the cluster is 14 times higher than the average annual visual field level by the simulation year of $Y_{10}$.

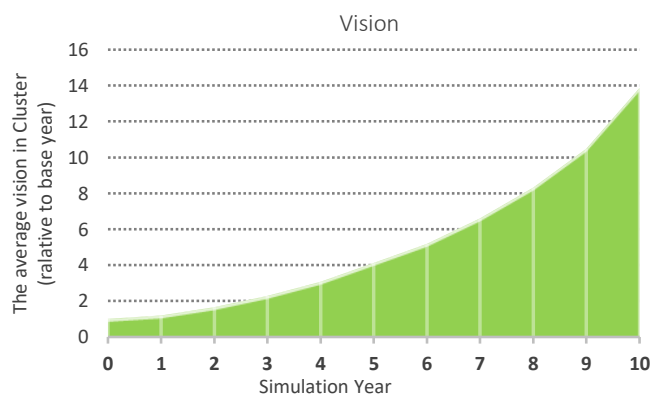

Figure 6. The evolution map of cluster average visual field

The results show that under the information-driven mechanism, cross-border e-commerce and manufacturing clusters have collaboratively improved the horizons and service capabilities of server agents, and expanded the overseas market of the cluster.

\section{Scenario 4}

In Scenario 4, to evaluate the technological progress mechanism, the average total transaction time $T_{C, t}$ of the cluster for server agents to process transactions and the average reproduction time $T_{C r, t}$ of the supplier agents in the cluster are observed in the simulated year of $Y_{t}$.

The simulation results shown in Fig.7 (a) illustrate that the total processing time of two types of the server agents in the cluster shows different trends: the transaction time of the traditional export server agent decreases year by year; in contrast, the transaction time of cross-border e-commerce server agent increasing year by year, but the total duration has been lower than traditional exports. 
As shown in Fig.7 (b), as the cluster evolves, the reproduction time decreases steadily year by year, and the reproduction time of cluster in the $Y_{10}$ is expected to drop to $91 \%$ of the base year of $Y_{0}$.

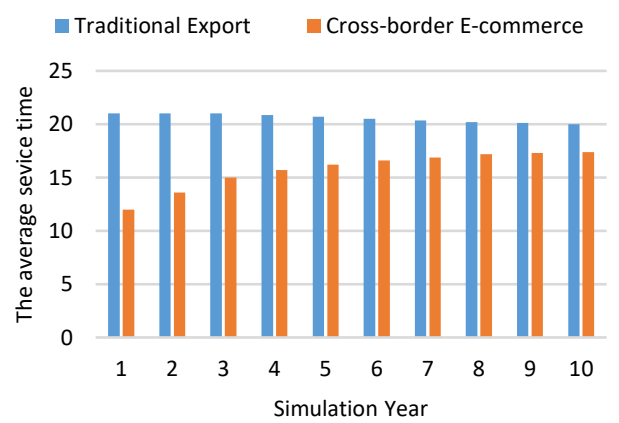

(a)

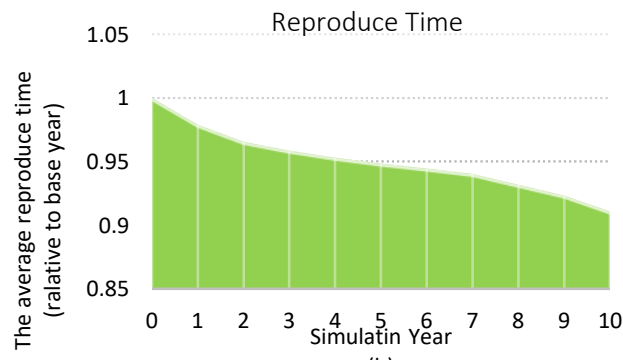

(b)

Figure 7. Evaluation Index Chart of Technology Progress

The results show that under the role of technological advancement mechanism, the service capability of traditional export server agents has been improved in the agent-based collaborative model, and the operation of cross-border e-commerce server agents are gradually standardized because they are constrained by the actions of the government which is one of the context agents, and the supplier agents' production mode changes and lead to reduce the reproduction time.

\section{SIMULATION ANALYSIS AND DISCUSSION}

This section will discuss the results of the agent-based collaborative model of four mechanisms, incorporate the role of the collaborative evolution mechanism in real economic operation, summarize the simulation results, and make feasible suggestions.

\section{A. Commodity circulation mechanism}

The simulation results of Scenario 1 show that under the commodity circulation mechanism, cross-border e-commerce collaborative with the manufacturing cluster bring about an increase in the total output of the cluster.

In the actual economic operation, cross-border e-commerce can obtain immediate market demand and consumption feedback by prompting the production end of the manufacturing cluster to directly face consumers. On the one hand, cross-border e-commerce has prompted manufacturers to innovate production models and change the organizational structure to better adapt to the market environment, on the other hand, the stable production capacity of the cluster guarantees the cross-border e-commerce service capabilities.

Therefore, the commodity circulation mechanism can be summarized like: cross-border e-commerce promotes its own service capabilities by transforming the attributes of commodities and innovating the manufacturing organization model of the manufacturing cluster.

\section{B. Fund circulation mechanism}

The simulation results of Scenario 2 show that cross-border e-commerce has the profit advantage of unit commodities in the early stage of the simulation. As the collaborative evolution proceeds, the profit advantage decreases or is even lower than the traditional export of the cluster. Meanwhile, we found that the higher the logistics transportation cost is, the greater the profit the supplier agents obtains. In particular, when the logistics cost is lower than a certain value, there are exceptions in the long run. The expected benefits of traditional export server agents do not affect the supplier agents' profit. On the contrary, the higher the expected income of cross-border e-commerce, the lower the unit goods profit of the supplier agents gains.

The flow of cross-border e-commerce funds in the real economy is different from the traditional international trade capital chain. First, the third-party payment platform obtains the buyer's payment; secondly, after the completion of the commodity transaction, the seller pays the goods; finally, the payment platform charges the platform operating fee. In theory, the capital chain process was simplified, reduced intermediate costs, and converted into producer profits, which was verified in the early stage of the simulation.

The logistics system within the cluster needs to be reformed to achieve further sustainable development. According to the simulation results, increasing the construction and the cost of logistics construction can enhance the supplier agent's unit commodity income in the evolution. At the same time, with the improvement of the logistics system, when the logistics cost is reduced to a certain extent, the supplier agents' unit commodity income will be higher than the standard model. The excessively high expected self-revenue of cross-border e-commerce within the cluster is not conducive to supplier agents to obtain higher unit commodity returns. To reduce the expected self-revenue of cross-border e-commerce, appropriate government support policies should be considered.

Therefore, the capital circulation mechanism can be summarized as: cross-border e-commerce and manufacturing clusters can reduce costs and increase profits through the integration and optimization of capital chains.

\section{Information-driven mechanism}

The results of Scenario 3 show that the information-driven mechanism simulated by the agent-based collaborative model can expand the horizon of server agents, promote information collection, enhance the services ability of matching supply and demand, and further promote the development of manufacturing clusters.

In the actual economic operation, when the manufacturing cluster develops to the later stage, the information interaction between agents within the cluster is blocked because the cluster is locked. By cooperating with cross-border e-commerce, a big data network is built, 
the data in the cluster can be analyzed and updated by agents to change its behavior, which ultimately gives the manufacturing cluster the power to transform and upgrade. According to the information-driven mechanism, when cross-border e-commerce collaborates with the manufacturing cluster, the perfect network layout of the upstream and downstream enterprises in the cluster, and the interconnection of the nodes in the industrial chain are indispensable.

Therefore, the information-driven mechanism is summarized as follows: cross-border e-commerce shares information in real time, provides upgrade momentum for the manufacturing cluster, and further enhances its own development momentum.

\section{Technological innovation mechanism}

Technological innovation is one of the important factors that affect the sustainable advancement of the coordinated evolution of the two clusters, while cross-border e-commerce cluster is an important driving force.

The simulation results of Scenario 4 show that under the technological progress mechanism, the server agent's transaction time is reduced, and the service capacity is improved; the supplier agent's reproduction time is shortened and the production capacity is improved.

During the simulation, it was also found that along with the guiding role of government actions of context agents, the total duration of the two types of server agents to process transactions shows different trends: the transaction duration of traditional export server agents decreases year by year, while the transaction duration of cross-border e-commerce server agents increasing year by year, and there is a tendency to converge. From the perspective of government guidance, the increase in the service time of cross-border e-commerce is due to the standardization of its own operations, while the decline in the transaction time of traditional exports comes from the construction of trade facilitation. Combining the characteristics of export-oriented economic development and the advantages of the two types of server agents, a combination model of "traditional trade export + cross-border e-commerce sales" will take advantages of the two clusters.

Therefore, the technological progress mechanism can be summarized as follows: cross-border e-commerce promotes technological innovation in the manufacturing cluster and provides industrial support for its own development.

\section{CONCLUSIONS}

Based on the theory of complex adaptive system (CAS), this paper establishes an agent-based collaboration model of cross-border e-commerce and manufacturing cluster. The collaboration model designs four potential driving interaction mechanisms. The following conclusions are obtained by observing the model dynamic collaborative evolution through the Repast Simphony simulation platform:

First, by comparing the proportion of cross-border e-commerce export scale based on the collaborative model simulation data with the data-based, the interaction mechanisms of the collaborative model was verified, which means the collaborative model is scientific and reasonable to provide a theoretical basis for reference for the co-evolution of the similar clusters;

Secondly, this paper designed four scenario simulations of the co-evolutionary mechanisms and conducted predictive analysis. Judging from the simulation results of agent-based collaborative model, in the simulation year of $Y_{10}$, the total output of the co-evolving cluster is $185 \%$ of the total annual output, the average horizon level has increased by 14 times, and the reproduction time will be reduced to $91 \%$ of the base year. Based on this, cross-border e-commerce can be seen as one of the feasible means for the transformation and upgrading of manufacturing clusters. In addition, when we conducted a scenario simulation of the fund circulation mechanism, we found that additional cross-border e-commerce support and the establishment of a cluster logistics system will promote the rise of manufacturing cluster revenue

Finally, the agent-based collaborative model extends the CAS theory and ABMS ideas in cross-border e-commerce research. The simulation conclusions may provide a reference to a certain extent for the development of cross-border e-commerce companies in export-oriented manufacturing clusters, which may help to achieve the transformation and upgrading of such clusters, provide a scientific basis for the government to assist cross-border e-commerce and manufacturing cluster collaboration.

In addition, the agent-based collaborative model can be expanded to the demand level (e.g., changes in the international market environment, personalization of customer needs) in the future research.

\section{ACKNOWLEDGMENT}

This research was supported by the National Natural Science Foundation of China (Grant No.71873073).

\section{REFERENCES}

[1] Yang Lihua, Zhong Yu. Some Thoughts on Promoting the Coordinated Development of Cross-border E-commerce and Manufacturing Clusters in China [J]. Journal of Shenyang University of Technology (Social Science Edition), 2018, 11 (06): 493-498.

[2] Wu Yunliang. Path selection and policy suggestions for the upgrading of manufacturing clusters in China $[\mathrm{J}]$. Macroeconomic Management, 2008, 000 (001): 51-54.

[3] Qin Kede, Qin Yue, Xu Changle, et al. Research on the transformation and upgrading of regional manufacturing industry under the background of deep globalization of manufacturing industry: Taking the transformation and upgrading of manufacturing industry in Jiaxing, Zhejiang as an example [J]. Science and Technology Progress and Countermeasures, 2013 (22): 49-53.

[4] Lundvall B, B. Borras. The globalizing learning economy: implication for innovation policy [C]. TESER Programmer Report, DG. Commission of the European Union, 1998.

[5] Zhicaiyi. Industrial Integration of Information and Communication Industry [J]. China Industrial Economy, 2001 (2): 24-27.

[6] Zhou Zhenhua. New Industrialization Road: Interaction and Integration of Industrialization and Informationization [J]. Shanghai Economic Research, 2002 (12): 5-7

[7] Zhang Zhiyong, He Jingshi, Gui Shouping, Lu Lifang. Research on logistics industry cluster service innovation-Based on the 
emergence mechanism of complex system [J]. Science and Technology Progress and Countermeasures, 2009, 26 (03): 75-77

[8] March J.G. Exploration and Exploitation in Organizational Learning [J], Organization Science, 1991, 1: 71-87

[9] Lewin A. Y., Chris P. Long, Timothy N. Carroll. The Co-Evolution of New Organizational Forms [J], Organization Science, 1999, 10 (5): 535-550

[10] McKelvey B .. Avoiding Complexity Catastrophe in Coevolutionary Pockets: Strategies for Rugged Landscapes [J], Organization Science, 1999,10 (3): 294-321

[11] Pan Ancheng. Research on the Sustainable Growth of Enterprises Based on the Co-evolution of Organizational Adaptability and Strategic Choice [PhD Thesis], Southeast University, 2006

[12] Sun Peng. Research on the collaborative development of modern logistics service industry and manufacturing industry based on complex system theory [D]. Central South University, 2012.

[13] Guo Qingjun, Zhou Yunfei, Yan Li. Empirical Research on Cooperative Evolution of Population Ecosystems in Manufacturing and Logistics [J]. Industrial Technology and Economy, 2014 (7): 9-18.

[14] Epstein, J. M. 2007. Generative Social Science: Studies in Agent-Based Computational Modeling. Princeton, NJ: Princeton University Press.

[15] Klügl, F., \& Bazzan, A.L.C. (2012). Agent-Based Modeling and Simulation. AI Magazine, 33 (3), 29.

[16] Vito Albino, Nunzia Carbonara, Ilaria Giannoccaro. Innovation in industrial districts: An agent-based simulation model [J]. Production economics, 2005,104: 31-45.

[17] Liu Wenrong. Systematic analysis of technological innovation mechanism [D]. Jilin University, 2009.

[18] Sun Hao, Xue Xiao. Experimental research on e-commerce ecosystem evolution based on multi-agent modeling [J]. Computer Engineering, 2016, 42 (07): 27-32 + 41.

[19] Li Fang, Yang Lihua, Liang Hanyue. Research on the mechanism and path of the coordinated development of cross-border e-commerce and industrial clusters in China $[\mathrm{J}]$. International Trade Issues, 2019 (02): 68-82

[20] Agent-Based Modeling Toolkits NetLogo, RePast and Swarm. Duncan A. Robertson. Academy of Management Learning \& Education, Vol. 4, No. 4 (Dec., 2005), pp. 525-527.

[21] Jing Caiyun, Chen Gang. Declining costs-an explanation of industrial clusters [J]. Accounting Research, 2011 (10): 79-83 + 99.

[22] Holland, John H. Hidden Order: How Adaptation Builds Complexity [J]. Leonardo, 1995, 29 (3).

[23] Ahokangas P, Hyry M, Rasanen P. Small Technology-based Firms in a Fast-growing Regional Cluster [J]. New England Journal of Entrepreneurship, 1999, 2. 